\title{
VERBALIZATION OF MAGIC CONCEPTS OF MODERN UKRAINIAN AND ENGLISH FANTASY
}

Kaidash Alla ${ }^{1}$

\section{Homych Victoria ${ }^{2}$}

DOI: https://doi.org/10.30525/978-9934-571-89-3_2

Becoming more and more popular, the fantasy genre of children's literature acquires broad scientific interpretations and acts as an object of linguistic research in connection with the plurality of depicted world planes, the multidimensionality of a figurative system, and the versatility of verbalized concepts.

\footnotetext{
${ }^{1}$ Nizhyn Mykola Gogol State University, Ukraine

${ }^{2}$ Separated Unit of the National University of Bioresources and Natural Resources Use of Ukraine "Nizhin Agrotechnical Institute", Ukraine 
A striking instance of the speculative fiction in contemporary British literature is Joanne Kathleen Rowling the creator of the 'Harry Potter' fantasy series. Since 1997 all seven books of Potterian have been capturing not only the children but also the adult readership.

A peculiar analogue of the English fantasy work is the contemporary novels with a deep national background of Ukrainian writer Dara Korniy. Built on a deep ethnoreligious culture, the texts of novels capture audience by reengineered author's mythological characters, a deep ideological orientation and original storylines.

In Ukrainian linguistic studies I. Alexandruk, A. Potapova, O. Solodova, I. Tersina have raised the issue of English-language fantasy in their dissertation papers. Linguists have focused on the time-spatial continuum, the composition of novels written by J. Rowling, the structural specificity of the linguistic units used in 'Harry Potter' books, the peculiarities of the translation.

A. Gurduz has attempted to make a comparative analysis of the English texts of J. Rowling and the Ukrainian-language novels of Dara Korniy. But the intertextual potencies of modern fantasy are so wide and multifaceted that they don't exhaust modern studies. One of the aspects of the conceptual scope of meta-texts are magic subjects, whose verbalization is accompanied by interesting semantic-stylistic paradigms. The article is dedicated to a study of the specifics of verbal images of the declared subject area in the comparative aspect of two English and Ukrainian writers' fiction sagas.

Both of these meta-texts have common and distinctive features. The focus is on teenagers: Harry Potter and Malva. Incredible adventures of these young people, which directly affect the formation of personality, form the basis of novels' plots.

The world of each of them is full of wonderful miracles, magicians, sorcerers and ordinary people coexisting in it. Heroes of both books are tangent to magic and ordinary worlds at the same time through the representatives of their families. Consequently, they are surrounded by ordinary people, without supernatural powers, and also wizards and different other magical creatures.

In addition to all these, there are many magic items in the life of Harry and Malva. They form the conceptual sphere which is verbalized in the texts.

By comparing Ukrainian and English meta-texts, we can conclude that some magic concepts have a similar functional orientation, while others are different. In the language outline of both sagas we can see the verbalization of concepts like "broom", "key", "stones", "powder", "extract", "mirror", "wand". Semantics of these verbal images of two authors sometimes coincides, sometimes actualizes the various semes.

An integral attribute of the magic world of both meta-texts is "potion". "The other side of twilight" novel by Dara Korniy laconically describes the potion as a basis of magical power of nature objects: It was necessary to make some kind of potion, which did not require the magic of the word, only the magic energy of herbs, the sun, maybe the moon, wind and water [2, p. 120]. "Harry Potter and the Prisoner of Azkaban" novel shows us the episode where students prepare the miniaturize potion, containing roots $[6$, p. 112]. The novel mentions wrinkling potion $[6$, p. 8], love 
potion [6, p. 66], wolfsbane potion [6, p. 309] - all of them are related to the plant world.

An interesting parallel can be drawn in the research of the linguistic expression collected with transportation. Peculiar means of transport in Potterian saga are floo powder, winged key, broom, thestral, motorcycle, knight bus.

A broom is traditional transportation in the world of wizards: He [Harry] lifted his right foot on the "Firebolt", firmly snatched the handle and felt the vibration of broomstick, as if it was itching itself to go up in the air more quickly [5, p. 57]. A similar reaction of the broomstick can be found in the Ukrainian text: The broomstick was barely oscillating in her hands [1, p. 78].

In "Harry Potter and the Deathly Hallows" novel the winged key was a "silver hair brush" [3, p. 59]. Before taking off the broom broke out in bright blue and it was necessary to touch it. So Harry and Hagrid flew away: Something jerked Harry in the navel area as if he had caught on an invisible hook, and dragged into a hole where he roused insanely, flying along with Hagrid from Mr. Tonks, without letting his finger off the broomstick. In a few seconds, his legs banged the scope of solid ground and he fell to his hands and knees on the yard "Balrog" [3, p. 60].

After the flight the broom was extinguished and thrown away. Similarly to this episode the picture of transportation in space is described in the novel "Harry Potter and the Goblet of Fire": And suddenly Harry felt a sharp jerk into the stomach. The legs were torn from the ground. He could not open his fist to let go of the Cup. And he dragged him along with Cedric onward through the curling of the wind and a massive whirlpool. ... Harry felt how his feet hit the ground [4, p. 579-580].

Another mean of conveyance in the English text is a living creature - thestral. Joan Rowling describes it, such as: ... The giant, robust thestral glanced up with rustle spread his hefty batting wings and again began to crop the grass [3, p. 74].

In "Harry Potter and the Prisoner of Azkaban" novel the author brightly describes the magic bus: Harry saw when he raised his head, to a triple-decker, violently purple bus, which had appeared out of thin air. Gold lettering over the windscreen spelled The Knight Bus [6, p. 35]; ... emergency transport for the stranded witch or wizard [6, p. 35]; There were no seats on the bus, only beds beside curtained windows with candles burning in brackets. At the each bed hooks candles were crackling, embossing wooden-paneled walls [6, p. 36]; The Knight Bus constantly drove onto the sidewalk, but did not touch anything there: lanterns, letterboxes and garbage cans were scratched everywhere, but just as it approached and then returned to their places [6, p. 37].

In the magical world of Dara Korniy, an interesting mean of transportation is the Jew's-harp. In the Ukrainian text, Jew's-harp is a musical instrument with magical properties. "Jew's-harp does not work around border, it's just a musical instrument. It is possible to get in here thanks to this tool, but there is impossible to be back" [1, p. 115].

Therefore, Malva needed to leave this world with the help of another magic object - a ball of yarn. Yagilka told the girl: Throw it to your feet. Hold firmly the end of the yarn. Follow the ball of yarn, he will show you the way [1, p. 116]. When you 
want to travel with the help of Jew's-harp you need to hang it around the neck and think about place. In "The other side of worlds" novel Malva calls the Jew's-harp a key [1, p. 26]. The words "jew's-harp" and "key" are synonymous in the meta-text of Dara Korniy: Led and Pollel teleported with the help of the key to the border fairly quickly and without difficulties. Much as Led had traveled more than one time to Yagilka's estate, he knew the road and was able to guide the jew's-harp in the right direction [1, p. 185].

Magic objects, verbalized in the English-language and Ukrainian-language fantastic meta-text, have both a common functional load, and certain distinctive features that give the author's works a peculiarity and uniqueness. The tangent semantic paradigms in the intertextual area promote the globalization of communicative processes and the understanding of the deep phenomena of national literatures. Individual author interpretation of such images presents the identity of each literary work.

In addition to magical subjects and things, analyzed meta-texts show a wide range of concepts, a thorough language analysis of which can be a subject of further linguistic studies.

\section{References:}

1. Kornij Dara. Zvorotny j bik svitiv [The reverse side of the worlds]. Kharkiv: Family Leisure Club, 2016. 316 p.

2. Kornij Dara. Zvorotny`j bik sutini [The reverse side of twilight]. Kharkiv: Family Leisure Club, 2016. 284 p.

3. Rowling J. K. Harry Potter and the Deathly Hallows. London: Bloomsbury, 2007. 607 p.

4. Rowling J. K. Harry Potter and the Goblet of Fire. London: Bloomsbury, 2000. 636 p.

5. Rowling J. K. Harry Potter and the Order of the Phoenix. London: loomsbury, 2003. 766 p.

6. Rowling J. K. Harry Potter and the Prisoner of Azkaban. London: Bloomsbury, 1999. 317 p. 